UCRL-JC-132099

PREPRINT

\title{
The Stand-Alone Microprobe at Livermore
}

\author{
M.L. Roberts \\ P.G. Grant \\ G.S. Bench \\ T.A. Brown \\ B.R. Frantz \\ D.H. Morse \\ A.J. Antolak \\ This paper was prepared for submittal to the \\ 6th International Conference on Nuclear Microprobe Technology and Applications \\ Stellenbosch, South Africa \\ October 11-16, 1998
}

October 2,1998

This is a preprint of a paper intended for publication in a journal or proceedings. Since changes may be made before publication, this preprint is made available with the understanding that it will not be cited or reproduced without the permission of the author. 


\section{DISCLAIMER}

This document was prepared as an account of work sponsored by an agency of the United States Government. Neither the United States Government nor the University of California nor any of their employees, makes any warranty, express or implied, or assumes any legal liability or responsibility for the accuracy, completeness, or usefulness of any information, apparatus, product, or process disclosed, or represents that its use would nol infringe privately owned rights. Reference herein to any specific commercial product, process, or service by trade name, trademark, manufacturer, or otherwise, does not necessarily constitute or imply its endorsement, recommendation, or favoring by the United States Government or the University of California. The views and opinions of authors expressed herein do not necessarily state or reflect those of the United States Government or the University of California, and shall not be used for advertising or product endorsement purposes. 


\section{The Stand-Alone Microprobe at Livermore}

M.L. Roberts, P.G. Grant, G.S. Bench, T.A. Brown, and B.R. Frantz

Center for Accelerator Mass Spectrometry

Lawrence Livermore National Laboratory

Livermore, CA 94551 USA

and

D.H. Morse and A.J. Antolak

Sandia National Laboratories/California

Livermore, CA 94551 USA

This paper was prepared for submittal to the

6th International Conference on Nuclear

Microprobe Technology and Applications

Spier Estate

South Africa

October 11-16, 1998 


\title{
The Stand-Alone Microprobe at Livermore
}

\author{
M.L. Roberts, P.G. Grant, G.S. Bench, T.A. Brown, and B.R. Frantz \\ Center for Accelerator Mass Spectrometry \\ Lawrence Livermore National Laboratory \\ Livermore, CA 94551 USA \\ and \\ D.H. Morse and A.J. Antolak \\ Sandia National Laboratories/California \\ Livermore, CA 94551 USA
}

\begin{abstract}
Lawrence Livermore National Laboratory (LLNL) and Sandia National Laboratories/California have jointly constructed a new stand-alone microprobe facility. Although the facility was built to develop a method to rapidly locate and determine elemental concentrations of micron scale particulates on various media using PIXE, the facility has found numerous applications in biology and materials science. The facility is located at LLNL and uses a General Ionex Corporation Model 358 duoplasmatron negative ion source, a National Electrostatics Corporation 5SDH-2 tandem accelerator, and an Oxford triplet lens. Features of the system include complete computer control of the beam transport using LabVIEW TM for Macintosh, computer controlled beam collimating and divergence limiting slits, automated sample positioning to micron resolution, and video optics for beam positioning and sample observation. Data collection is accomplished with the simultaneous use of as many as four EG\&G Ortec IGLET-XTM X-Ray detectors, digital amplifiers made by X-Ray Instruments and Associates (XIA), and LabVIEWTM for Macintosh acquisition software.

This work performed under the auspices of the U.S. Department of Energy at the I awrence Livermore National Laboratory under contract W-7405-Eng-48 and at Sandia National Laboratories/California under contract DE-AC04-94AL85000.
\end{abstract}

Keywords:

Corresponding Author: Mark L. Roberts L-397, P.O. Box 808

LLNL

Livermore, CA 94550

Fax: (925) 423-7884

E-mail: roberts5@llnl.gov 


\section{Introduction}

Lawrence Livermore National Laboratory (LLNL) and Sandia National Laboratories/California (SNL) have jointly constructed a new stand-alone microprobe facility. The facility is located at LLNL but is jointly run by SNL and LLNL personnel. The new facility is primarily used for Particle Induced X-Ray Emission (PIXE), Scanning Transmission Ion Microscopy (STIM), and Ion Micro-Tomography (IMT) analyses. Applications range from particulate analysis to materials science to biology. Details of the new stand-alone facility and a summary of recent applications will be discussed.

\section{Details of the System}

A picture of the new stand-alone microprobe facility is shown in Figure 1. In the system, $\mathrm{H}^{-}$ions are produced using a General Ionex Model 358 Duoplasmatron source. The $\mathrm{H}^{-}$ions are then mass/energy analyzed by the low energy injection magnet and injected into a National Electrostatics Corporation 5SDH-2 tandem accelerator. The maximum operating voltage of the accelerator is $1.7 \mathrm{MV}$ but normal operating voltage is $1.5 \mathrm{MV}$ to produce approximately $3.0 \mathrm{MeV}$ protons. Beam stripping is accomplished using either $1 \mu \mathrm{g} / \mathrm{cm}^{2}$ carbon foils or a pumped gas stripper. After exiting the accelerator, the $3.0 \mathrm{MeV}$ protons are mass/energy analyzed by the high energy analysis magnet and injected into the microprobe beamline. The beamline for this stand-alone system is similar to the beamline used on LLNL's $10 \mathrm{MV}$ tandem accelerator $^{[1]}$. One unique feature of these beamlines is the use of three cast iron box beams sitting on sand filled piers to provide a rigid beamline structure. The box beams are approximately $10 \mathrm{~cm}$ wide by $15 \mathrm{~cm}$ tall with a wall thickness of $1.3 \mathrm{~cm}$. The upper of the three box beams serves as the beam pipe or vacuum vessel for the ion beam. Because it is made of iron, the upper box beam also provides integral shielding from the effects of stray magnetic fields.

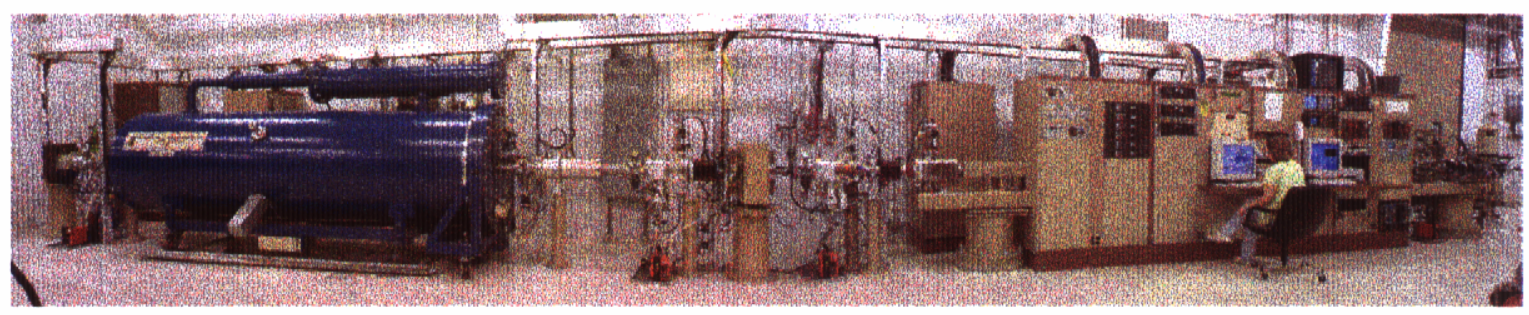

Figure 1. The new stand alone microprobe at Lawrence Livermore National Laboratory. The low energy injection magnet can be seen on the extreme far left, the accelerator is center left, the analysis magnet is in the center, while the microprobe beamline is on the right.

Operation of the stand-alone microprobe facility is accomplished using a computer control system. A display screen for the computer control system is shown in Figure 2. The computer control stem is based on LabVIEW ${ }^{\mathrm{TM}}$ for Macintosh and uses CAMAC based Digital-to-Analog Converters, Analog-to-Digital Converters, Input/Output Registers, and Group 3 ControlNet fiber optic communications. Communication between the computer and the CAMAC crate is accomplished using GPIB. All aspects of the beam transport are computer controlled including the ion source, accelerator, beam bending magnets, steerers, lenses, Faraday cups, beam profile monitors, the collimating slits, the divergence limiting slits, and the 
Oxford quadrupole triplet. Because the computer control system can save and recall operating parameters, system startup is rapid and precise. From initial startup, it is not unusual to begin data taking activities in less than 5 minutes.
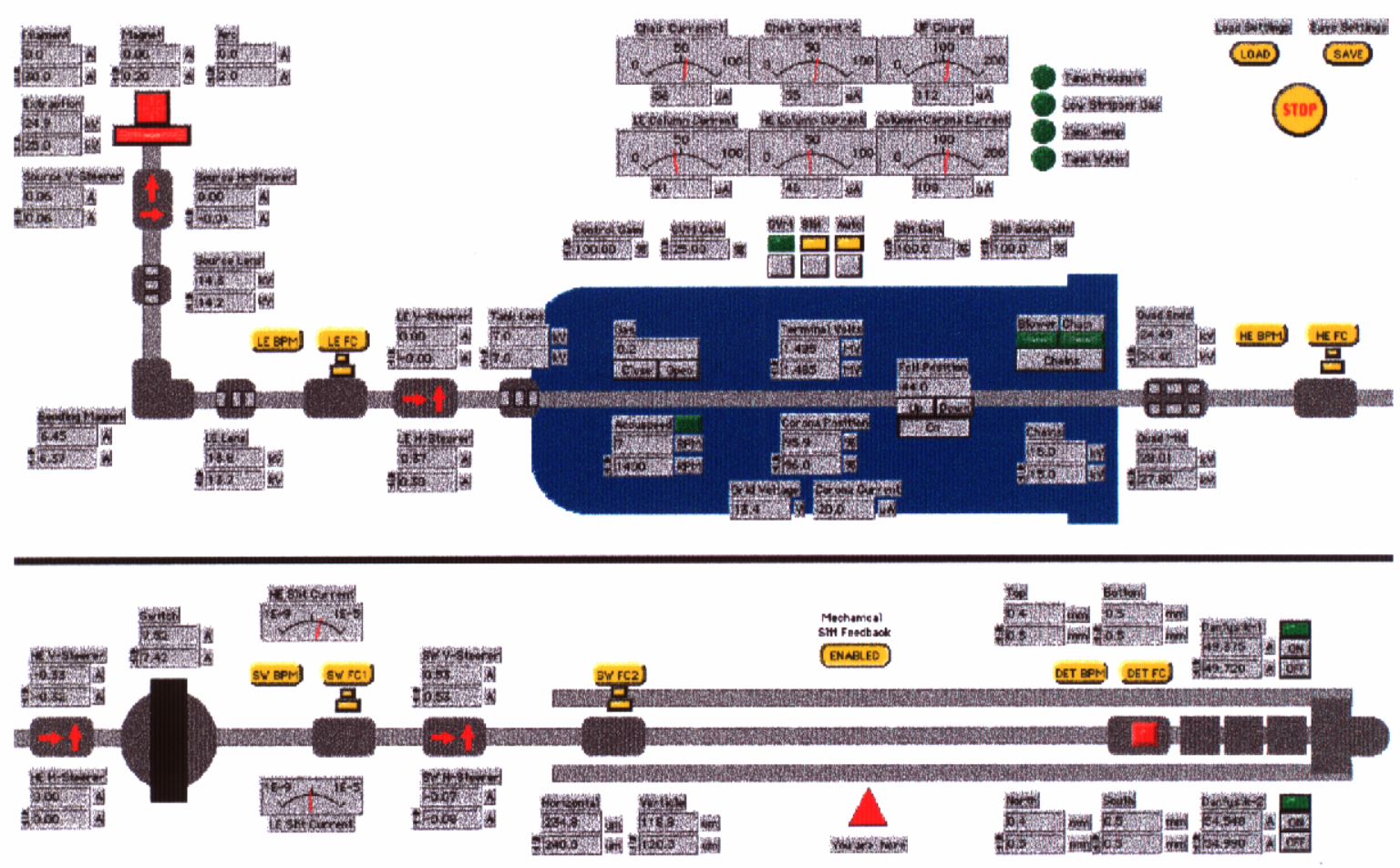

Figure 2. Display screen for the LabVIEW ${ }^{\mathrm{TM}}$ based computer control system.

A picture of the target chamber used on the new stand-alone microprobe facility is shown in Figure 3 . The body of the target chamber is rectangular with a depth of $190 \mathrm{~mm}$, a width of $270 \mathrm{~mm}$, and a height of 760 $\mathrm{mm}$. The chamber is pumped by a $500 \mathrm{l} / \mathrm{s}$ Pfeiffer turbomolecular drag pump. After samples have been inserted, it normally takes less than 30 minutes to achieve an operating vacuum of approximately $1 \times 10^{-6}$ Torr. For analyses that cannot be performed in vacuum, an external beam capability is achieved by placing an ultra thin $\mathrm{Si}_{3} \mathrm{~N}_{4}$ window over the beam entry port to the target chamber and then back filling the target chamber to slightly below atmospheric pressure with helium.

Attached to the target chamber are various video cameras. These cameras provide multiple views and magnifications of the sample ladder, beam position, and sample morphology. Depending on the camera and multiplier lens used, magnifications of $1,26,1430$, or 1430 to 4500 can be achieved as viewed on a 19 inch monitor. Two microscope lens assemblies are used to image sample morphology and microscopic placement of the beam. The first of these microscope lenses is mounted in front of the sample and images the sample and ion beam by way of a mirror mounted at $45^{\circ}$. To allow passage of the ion beam, the mirror has a $3 \mathrm{~mm}$ hole in its center. The second microscopic lens is mounted behind the sample and can only be used with transparent samples. Because the rear viewing microscope can approach closer to the surface of the sample than the front viewing microscope, objectives with a higher magnification and a shorter working distance can be 
used. The disadvantage of the rear viewing microscope is that it must be removed from the beam center line to collect beam charge when performing PIXE measurements. Sample illumination is accomplished using a fiber optic illuminator and various viewports. Video signals from any of the cameras can be directed by two video switches to a large monitor, a video micrometer with contrast enhancement, or a video capture card.

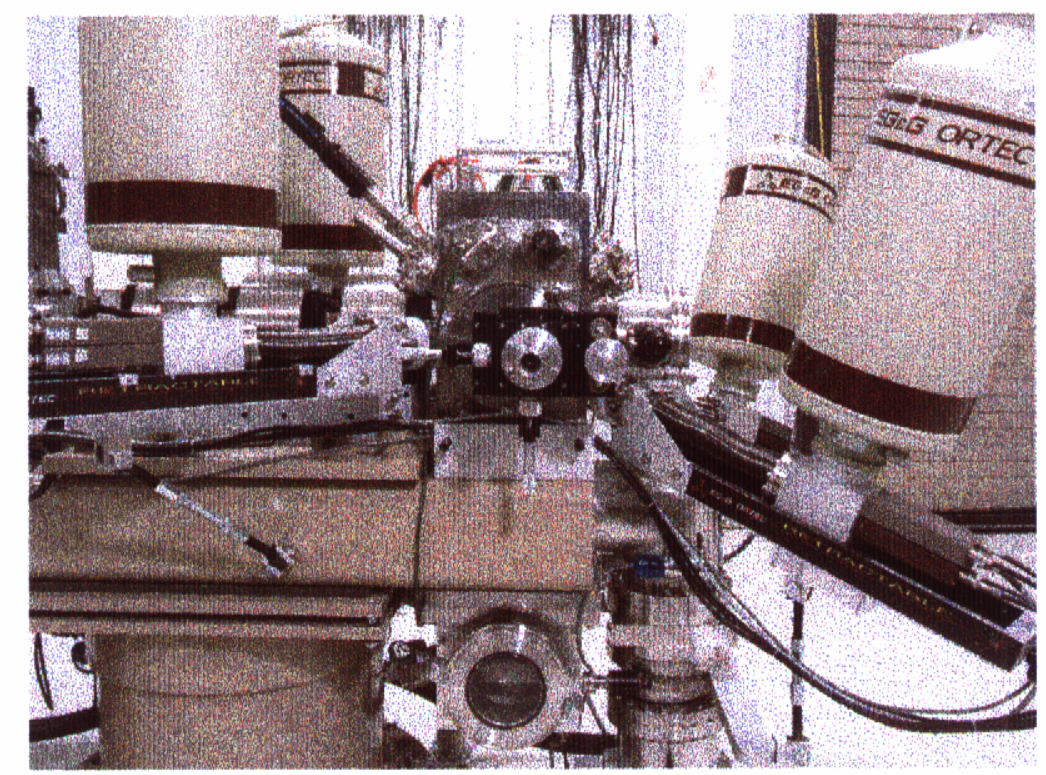

Figure 3. The target chamber on the new stand-alone microprobe facility. One can see the four EG\&G Ortec IGLET-X ${ }^{\mathrm{TM}} X$-Ray detectors surrounding the central target chamber. The Oxford quadrupole triplet can be seen on the left between the two back angle X-Ray detectors.

Sample movement is accomplished using a Newport motion controller and manipulator. Samples can be moved up to $100 \mathrm{~mm}$ along the $\mathrm{x}$-axis and up to $150 \mathrm{~mm}$ along the y-axis with 1 micron resolution and 2 micron repeatability. The samples can also be rotated for IMT analyses.

For PIXE analyses, we can simultaneously collect data from as many as four EG\&G Ortec IGLET-X ${ }^{\mathrm{TM}} \mathrm{X}$-Ray detectors. Each of these detectors has an active area of $200 \mathrm{~m} \mathrm{~m}^{2}$ and an energy resolution of better than $160 \mathrm{eV}$ at 5.9 $\mathrm{keV}$. These detectors are capable of measuring X-Ray energies as low as the carbon $\mathrm{K} \alpha$ line and have efficiencies close to $100 \%$ for energies up to $45 \mathrm{keV}$. Two of the detectors are located at back angles while the other two detectors are located at a forward angle. Using all four detectors simultaneously, it is possible to achieve an active detection area of greater than $1 \mathrm{sr}$. For STIM and IMT analyses, residual ion energies are measured using a retractable, charge-particle silicon surface barrier detector located approximately $5 \mathrm{~cm}$ behind the sample.

Data acquisition and data analysis on the new stand-alone microprobe facility are accomplished using a LabVIEW ${ }^{\mathrm{TM}}$ for Macintosh based system that is discussed elsewhere ${ }^{[2]}$. On-line histogram and elemental map displays provide a user friendly data acquisition interface while off-line data analysis allows the generation of elemental maps, PIXE spectral analysis, and 
tomographic reconstruction of IMT data.

As a test of beam spot size on the new stand-alone microprobe facility, we performed a two-dimensional and one-dimensional scan of a focused 250 pA $3 \mathrm{MeV}$ proton beam across an electroformed $\mathrm{Cu}$ mesh grid. The result of this scan is shown in Figure 4. With the assumption of a gaussian shaped beam and perfectly sharp grid edges, a spatial resolution of less than 1.2 microns is indicated.

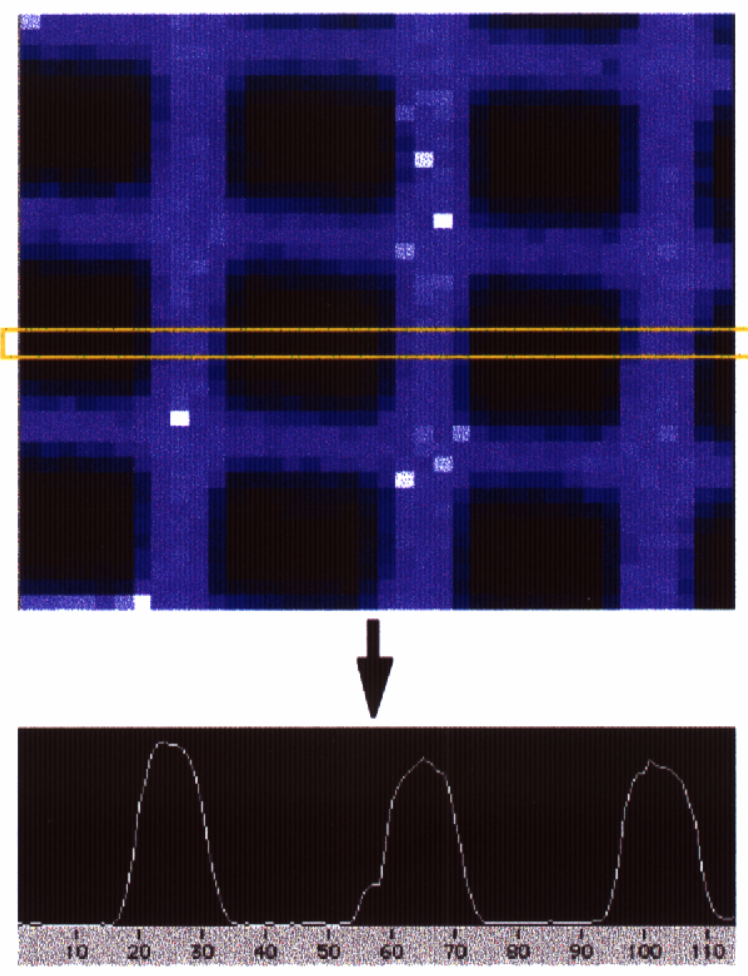

Figure 4. A two-dimensional and one-dimensional line scan of a focused 250 pA $3 \mathrm{MeV}$ proton beam across an electroformed $\mathrm{Cu}$ mesh grid. Grid spacing is 12.75 microns. With the assumption of a gaussian shaped beam and perfectly sharp grid edges, a spatial resolution of 1.2 microns is indicated.

One problem that was observed on the new microprobe facility was a vertical drift of the beam spot during long run time analyses. This vertical beam drift was particularly noticeable on hot days. The source of this drift was eventually traced to our Oxford lenses. It was found that as our Oxford lenses warmed up, that they would expand, and that since the lenses sit on a manipulator base, the center of the lenses would shift upwards relative to the center of the beam. This upwards shift in the lenses would cause our beam spot to appear to drift down. This shift could be as large as 165 microns over a period of 8 hours. To prevent this shift, we now fan cool our Oxford lenses and try to avoid turning them off.

\section{Recent Measurements}

The new stand-alone microprobe facility was originally built to develop a method to rapidly locate and determine elemental concentrations of micron scale particulates on various media using PIXE ${ }^{[3]}$. Quantitative analysis of micron-scale particulates on filters is important in several application areas 
such as determining the composition of air- or water-borne environmental pollutants or for arms control and test ban treaty verification applications. One application area has been analyses of Lake Tahoe water filters. Lake Tahoe is a large high elevation lake located in the Sierra Nevada mountains on the border between the states of California and Nevada. While the lake is noted for its extremely clear water, the past 40 years have seen a dramatic decrease in Lake Tahoe water clarity. One possible explanation for this decrease in water clarity is run-off from the increased urbanization of the Lake Tahoe basin. To study the particulates being discharged into Lake Tahoe, polycarbonate water filters were obtained from the mouths of three streams that empty into Lake Tahoe. One of these streams drained from an area that was largely urban in nature, the second steam discharged from an area that had source material that was largely volcanic in nature, while the final stream discharged from an area that had source material that was largely of granitic origin. Bulk PIXE analyses of the filter papers from these three stream types were obtained and bulk differences in elemental content were seen. To better understand the differences in bulk PIXE analyses, micro-PIXE analyses were performed on the filter papers to look for differences in elemental makeup of individual particulates on the filters. Figure 5 shows a large area PIXE scan from the 'granite' type stream. While much work remains, it is hoped that analyses of particulates that flow into Lake Tahoe can lead to a better understanding of the decrease in Lake Tahoe water clarity.

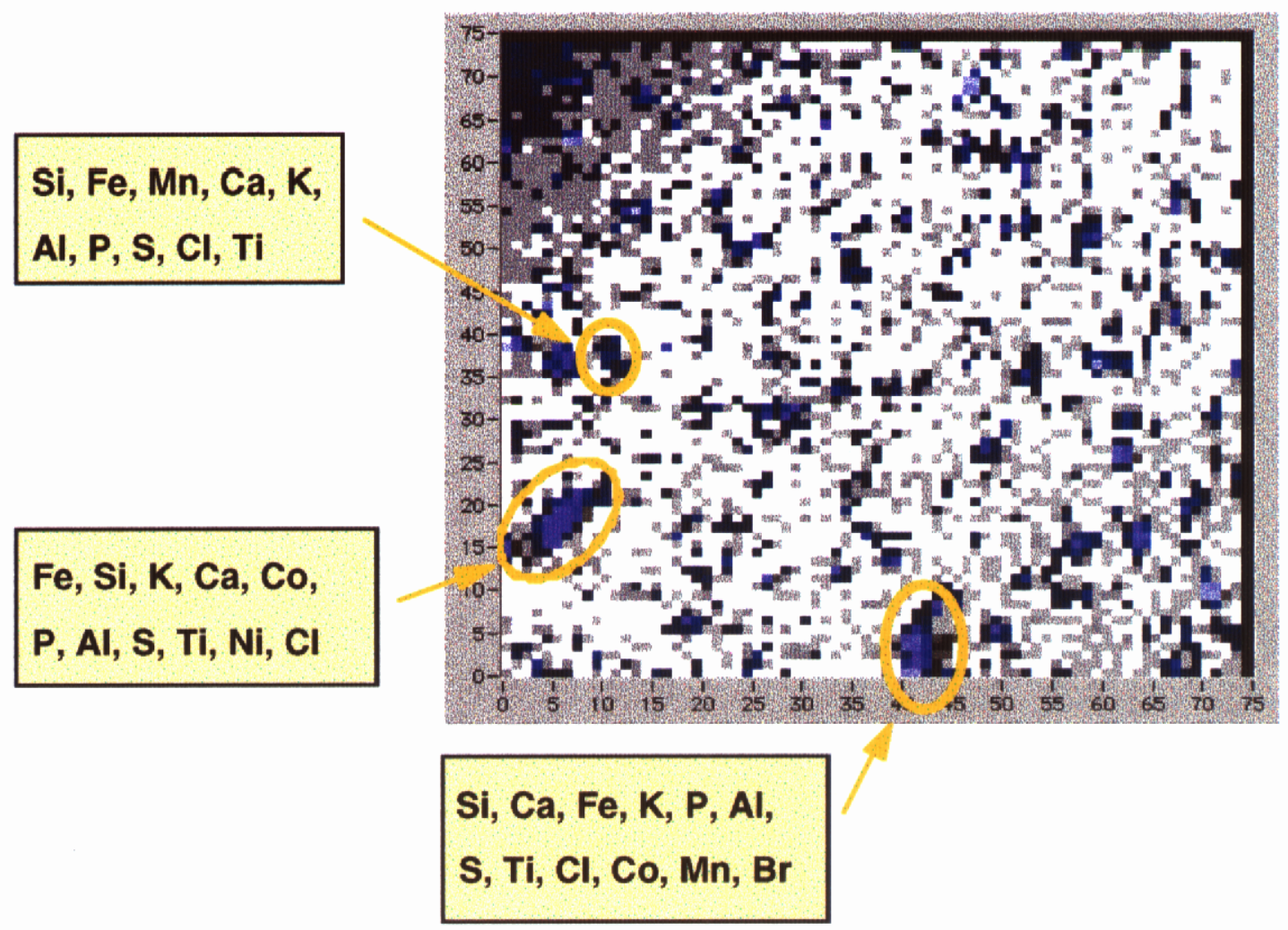

Figure 5. Large area $(1 \mathrm{~mm} \times 1 \mathrm{~mm})$ PIXE scan of a Lake Tahoe water filter. The beam spot size was approximately 13.5 microns.

As opposed to bulk PIXE analyses, one can use micro-PIXE to obtain elemental analyses of individual particulates. Elements are listed in order of decreasing concentration. 
Although the new facility was built to develop a method to rapidly locate particulates on media, the new facility has found numerous applications in biology and materials science. Many of these applications have been reported elsewhere and will not be described here ${ }^{[4,5,6,7]}$. One interesting application, however, has been the use of the microprobe to better understand the distribution pattern of mineral elements in lichen tissues. Figure 6 shows data from a PIXE and STIM scan of a lichen cross section. While the specific mechanism is not clearly understood, it is generally accepted that lichens receive most of their mineral nutrients from atmospheric out wash, with minimal input from the substrate $\mathrm{e}^{[8]}$. The data shown in Figure 6 suggest that the nuclear microprobe may be useful in elucidating element absorption and transport mechanisms in lichens. This research may also enhance efforts to use lichens in bio-monitoring of air quality.

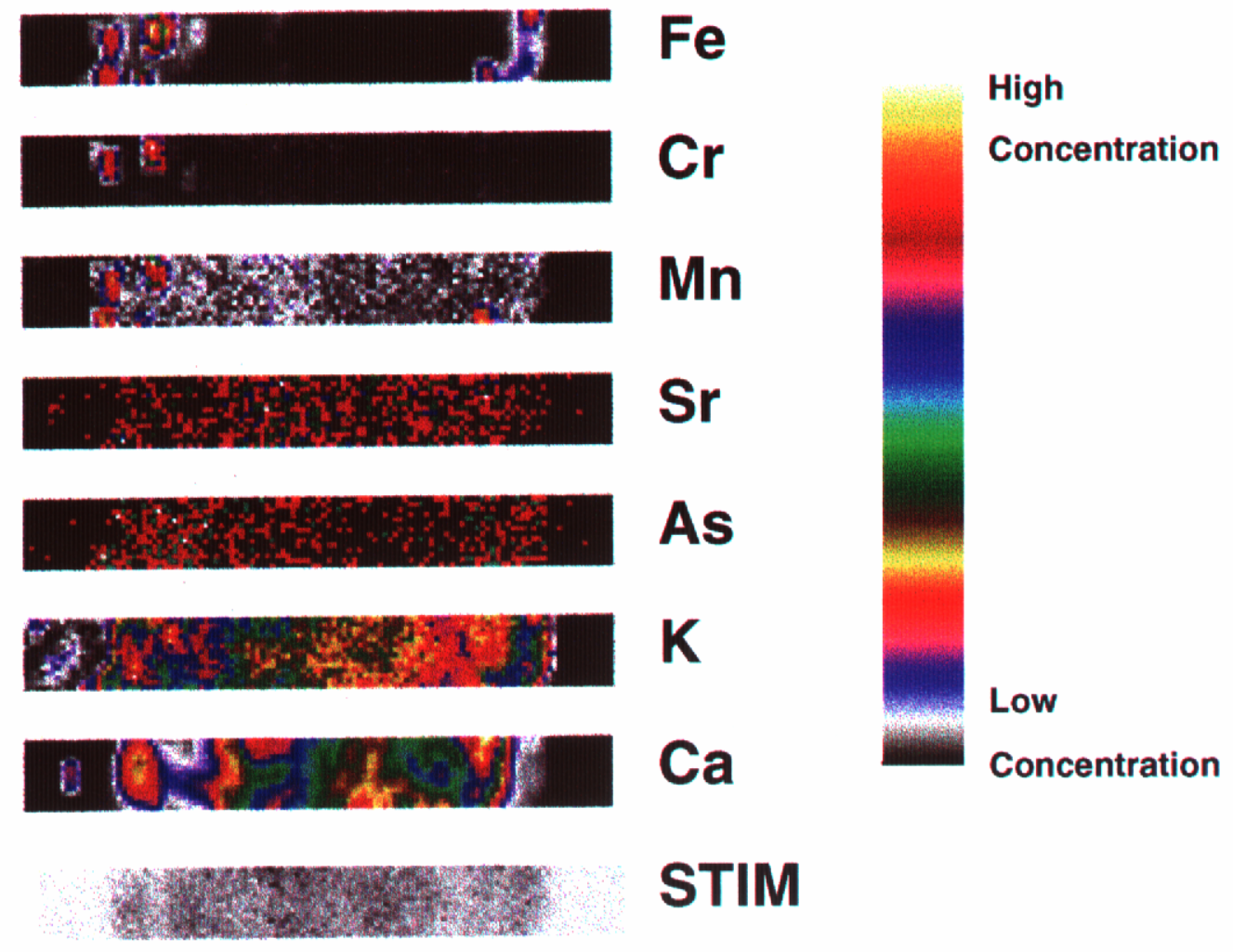

Figure 6. PIXE and STIM scan of lichen cross section.

\section{Summary}

Lawrence Livermore National Laboratory (LLNL) and Sandia National Laboratories/California have jointly constructed a new stand-alone microprobe facility. Key features of the new system include complete computer control of the beam transport, automated target positioning to micron resolution, the use of video optics for beam positioning/sample observation, and the ability to simultaneously collect data from as many as four energy dispersive X-Ray detectors. With this new facility, we have applied the techniques of micro-PIXE and STIM for use in particulate analysis, materials science, and biology. 


\section{References}

[1] M.L. Roberts, G.S. Bench, D.W. Heikkinen, D.H. Morse, P.R. Bach, and A.E. Pontau, 'The new nuclear microprobe at Livermore,' Nuclear Instruments and Methods in Physics Research, B104 (1995) 13-18.

[2] D.H. Morse, A.J. Antolak, G.S. Bench, and M.L. Roberts, 'A flexible LabVIEW'TM-based data acquisition and analysis system for scanning nuclear microscopy,' These proceedings.

[3] A.J. Antolak, D.H. Morse, D.W. Heikkinen, M.L. Roberts, and G.S. Bench, 'In situ characterization of micron-scale particles by nuclear microscopy,' Nuclear Instruments and Methods in Physics Research, B130 (1997) 211-218.

[4] R.J. Mauthe, E. Sideras-Haddad, K.W. Turteltaub, and G.S. Bench, 'Quantitative imaging , microscopy for the sensitive detection of administered motal containing drugs in single cells and tissue slices - a demonstration using platinum based chemotheraputic agents,' Journal of Pharmaceutical and Biomedical Analysis, 17 (1998) 651-663.

[5] G.S. Bench, M.H. Corzett, L. Deyebra, R. Oliva, and R. Balhorn, 'Protein and DNA contents in sperm from an infertile human male possessing protamine defects that vary over time,' Molecular Reproduction and Development, Volume 50, N3 (1998) 345-353.

[6] G.S. Bench, A.M. Friz, M.H. Corzett, D.H. Morse, and R. Balhom, 'DNA and total protamine masses in individual sperm from fertile mammalian subjects,' Cytometry, 23 (1996) 263-271.

[7] M.Q. Man, T. Mauro, G.S. Bench, R. Warren, P.M. Elias, and K.R. Feingold, 'Calcium and potassium inhibit barrier recovery after disruption, independent of the type of insult in hairless mice,' Experimental Dermatology, Volume 6, N1 (1997) 36-40.

[8] B.M. Clark, N.F. Mangelson, L.L. St. Clair, ].S. Gardner, L.S. Cooper, L.B. Rees, P.G. Grant, and G.S. Bench, 'Analysis of lichen thin sections by PIXE and STIM using a proton microprobe,' Accepted for publication in Nuclear Instruments and Methods in Physics Research. 